\title{
Amelioration of Sarcoptic Mange-Induced Oxidative Stress and Apoptosis in Dogs by Using Calendula officinalis Flower Extracts
}

\author{
Shanker K. Singh ${ }^{1,2}$ and Umesh Dimri ${ }^{1}$ \\ ${ }^{1}$ Division of Medicine, Indian Veterinary Research Institute, Izatnagar, Bareilly 243 122, India \\ ${ }^{2}$ Department of Veterinary Medicine, College of Veterinary Science and Animal Husbandry, DUVASU, Mathura 281 001, India
}

Correspondence should be addressed to Shanker K. Singh; pshankervet@gmail.com

Received 4 June 2013; Accepted 2 September 2013

Academic Editors: F. Antunes, P. Leroy, and A. Shukla

Copyright (C) 2013 S. K. Singh and U. Dimri. This is an open access article distributed under the Creative Commons Attribution License, which permits unrestricted use, distribution, and reproduction in any medium, provided the original work is properly cited.

\begin{abstract}
Twenty-four clinically Sarcoptes-infested dogs were randomly enrolled into three groups (groups A, B, and C), 8 dogs in each group. Group A was treated with ivermectin + Calendula officinalis flower extract (CFE). Group B was treated with ivermectin + $\mathrm{N}$-acetyl cysteine (NAC) (standard positive controls), while group C (negative control) was treated with ivermectin alone. Another eight healthy dogs were used as healthy controls (group D). By day 28 after therapy, the dogs treated adjunctly with CFE as well as with $\mathrm{N}$-acetyl cysteine revealed significant $(P \leq 0.001)$ amelioration of the altered markers of oxidative stress towards normalcy. The dogs of these groups also revealed significant $(P \leq 0.001)$ amelioration of apoptotic leukocytes towards normalcy, and values were comparable to those of the healthy controls. While by day 28 after therapy, ivermectin alone treated dogs could not achieve comparable values to those of the healthy controls. The dogs treated adjunctly with CFE and N-acetyl cysteine also revealed faster parasitological as well as clinical cure rate as compared to the ivermectin alone treated dogs. In conclusion, CFE has remarkable antioxidant and antiapoptotic potential and can constitute a potential adjunctive remedy with miticide for the therapeutic management of canine sarcoptic mange.
\end{abstract}

\section{Introduction}

Sarcoptic mange is a highly contagious and pruritic acariosis of the skin affecting abroad host range including more than 100 mammalian species belonging to 27 families from 10 orders $[1,2]$ and afflicts 300 million people globally. In many animal species, the prevalence of sarcoptic mange is very high and an untreated animal often succumbs $[3,4]$. In addition to its potential to cause huge economic loss due to reduced production and increased mortality in animals, $[1,5]$ it is an emerging/reemerging infectious disease that threatens human and animal health globally [6-8]. In developing countries, it is a significant public health problem because it is highly prevalent and complications are frequent [9].

Emerging resistance to the currently available therapeutic permethrin and ivermectin has recently been reported from regions where previously effective acaricides have been used extensively in socially disadvantaged communities and in some developing countries [10-12]. In addition, drug residue can build up during extensive and long-term use, which poses environmental hazards and can lead to increased drug resistance in the target species $[10,13]$. This emphasizes the need to identify potential targets for chemotherapeutic and/or immunological intervention.

Some of the most important predisposing factors for the development of sarcoptic mange are known to include the immune status of the animal, nutritional status, and oxidative stress [14-16]. Recently, we have also demonstrated the involvement of oxidative stress and increased apoptosis of peripheral blood leukocytes in pathogenesis of canine sarcoptic mange [17]. The current wide prevalence and decreasing treatment efficacy of sarcoptic mange necessitate the need for novel control strategies in the form of adjunctive alternative therapies. 
In this context, much attention has been paid to antioxidants from natural sources, especially flavonoids and other phenolic compounds [18]. Various flavonoids (e.g., quercetin, apigenin, and tea catechins) have been shown to have anti-inflammatory activity by inhibiting cyclooxygenase- 2 (COX2) and inducible nitric oxide synthase [19], which are related to antioxidant activity. Flavonoids may inhibit cytosolic and tyrosine kinase [20,21] and neutrophil degranulation [20]. Calendula officinalis L. (Asteraceae) is cultivated for ornamental and medicinal purposes in Europe, China, USA, and India. It is used mainly for cutaneous and internal inflammatory diseases of several origins [22]. The main chemical constituents of $C$. officinalis include steroids, terpenoids, free and esterified triterpenic alcohols, phenolic acids, flavonoids (quercetin, rutin, narcissin, isorhamnetin, and kaempferol), and other compounds [23]. Calendula flowers contain large quantities of antioxidant compounds (flavonoids and polyphenols), suggesting that they may possess antioxidants to ameliorate sarcoptic mange-induced oxidative and immunological disparities. Keeping these facts under consideration, the present study was projected with the aim of determining the protective effect of Calendula officinalis flowers extract against sarcoptic mange-induced oxidative stress and apoptosis of leukocytes in dogs.

\section{Materials and Methods}

2.1. Plant Materials and Preparation of Extracts. Seedlings of C. officinalis were obtained from an authorized herbalist and cultivated organically. After complete blooming, the whole flower pods were harvested between 9 a.m. to 3 p.m. GMT; petals were separated and subjected to the shade to dry. Dried flowers were grinded to make the powder. The powder was subjected to ethanol (80\%) extraction in Soxhlet apparatus and was concentrated under reduced pressure. Finally, CFE was dispensed in capsules and given orally to the infested dogs.

2.2. Animal Selection Criteria and Design of the Study. The dogs enrolled in the study were recruited among the patients presented for clinical and dermatological examination. All diseased dogs were naturally infested with S. scabiei var. canis and were reported to be suffering from the clinical disease for at least 15 days before presentation. None of the dogs had been treated with ectoparasiticides or steroidal anti-inflammatory drugs in the last 30 days before obtaining the first blood samples. On microscopic examination, stool samples of all enrolled dogs were found negative for helminth parasite eggs by sedimentation technique. The diseased dogs were also free from ectoparasites apart from the S. scabiei var. canis mite infestation.

Clinical diagnosis of sarcoptic mange was based on the following six clinical inclusion criteria: (1) intense pruritus, (2) papular eruption (abdomen, inner leg region, and thorax), (3) self-trauma, (4) excoriations, (5) alopecia, and (6) crusting of the elbow, ear margins, and hocks. Severity of Sarcoptesinduced skin lesions was also scored. Seven clinical symptoms (pruritus, erythema, papules, excoriations, crusts (scabs), alopecia, and pyoderma lesions) were assessed and rated on a scale from 0 (absent) to (severe 3 ). The seven scores were added up and expressed as a Sarcoptes-induced skin lesions score (SSLS) that could have values between 0 and 21 [24]. Dogs were included in the study only if S. scabiei var. canis mites or mites with their developmental stages were found in microscopic examination of material from up to six deep skin scrapings and revealed at least three clinical inclusion criteria. Diseased dogs were examined at weekly intervals throughout the study period. The main efficacy criterion was the parasitological cure rate, which was calculated as the proportion of dogs negative for S. scabiei var. canis mites on the basis of microscopic examination of deep skin scrapings obtained on days 14, 21, and 28 after the treatments. On days 0,14 , and 28, presence and severity of Sarcoptes-induced skin lesions were scored and used as secondary efficacy criteria.

Twenty-four Sarcoptes-infested dogs (9 intact males and 15 intact females) of 12-48-month age groups were selected for the study ( 8 mongrels, 6 German Shepherds, 4 Labrador Retrievers, and 3 each of Pomeranians and pugs) and were allocated randomly into three groups (groups A, B, and C), with 8 dogs in each group. Another eight 12-48-month-old clinically healthy dogs (3 Mongrels, 2 Labrador Retrievers and 1 each of Pomeranians, German Shepherds, and pugs) of either sexes (5 intact males and 3 intact females) were used as controls (group D). These dogs were also free from ectoparasites and helminth parasites on microscopic examinations of skin scraping materials and stool samples, respectively. The dogs of group A were subcutaneously given a commercial formulation of ivermectin $1 \% \mathrm{w} / \mathrm{v}$ solution at a dose rate of $0.2 \mathrm{mg} / \mathrm{kg}$ once weekly $+\mathrm{CFE}$ at a dose rate of $50 \mathrm{mg} / \mathrm{kg}$ orally, once every day. (The $50 \mathrm{mg} / \mathrm{kg}$ once daily dose of CFE was selected from a preliminary study conducted on mice (unpublished). In this study, CFE was given at the doses of 50,100 , and $200 \mathrm{mg} / \mathrm{kg}$ to protect the mice against cadmium chloride-induced oxidative stress). The dogs of group B were subcutaneously given a commercial formulation of ivermectin $1 \% \mathrm{w} / \mathrm{v}$ solution at a dose rate of $0.2 \mathrm{mg} / \mathrm{kg}$ once weekly $+\mathrm{N}$-acetyl cysteine at a dose rate of $70 \mathrm{mg} / \mathrm{kg}$ orally twice a day as a standard antioxidant and were kept as positive standard controls, while the dogs of group $\mathrm{C}$ were treated subcutaneously with ivermectin alone at a dose rate of $0.2 \mathrm{mg} / \mathrm{kg}$ once weekly. As the dogs were client owned, it was unfeasible to standardize the diets for all animals. However, as per the owners, all the dogs were managed on a similar diet (mainly rice, chapatti, wheat dalia, milk, eggs, and cooked chicken and goat meat).

2.3. Blood Samples. Approximately a $5 \mathrm{~mL}$ of blood sample was obtained from each Sarcoptes-infested dog in EDTA containing tubes at day 0 before the start of the therapy and at day 28 after treatment. Further, blood samples were subjected to assays of oxidative stress and apoptosis. Single $5 \mathrm{~mL}$ of blood sample was also obtained from each healthy dog to determine the studied parameter and was used as a comparative standard.

2.4. Assays of Oxidative Stress. In order to evaluate the ameliorative potential of CFE adjunct therapy on sarcoptic 
mange-induced oxidative stress, the markers of oxidative stress, for instance, levels of lipid peroxides, malondialdehyde (MDA), and potential antioxidant reduced glutathione (GSH) as well as the activities of antioxidant enzymes: glutathione peroxidase (GSH-Px), glutathione-S-transferase (GST), superoxide dismutase(SOD), and catalase (CAT) were determined in erythrocytes of dogs.

2.4.1. Preparation of Haemolysate and RBC Suspension. For assays of oxidative stress, $3 \mathrm{~mL}$ of blood samples from each dog were centrifuged at $200 \times \mathrm{g}$ for $10 \mathrm{~min}$ to harvest the erythrocytes. Erythrocytes were washed thrice with normal saline solution, and finally, $10 \%$ haemolysate was prepared by adding chilled distilled water. For estimation of reduced glutathione, RBC suspension was prepared by adding equal volume of erythrocytes and normal saline solution. Haemolysate and $\mathrm{RBC}$ suspension were kept at $-70^{\circ} \mathrm{C}$ and were used for antioxidant assay within $6 \mathrm{~h}$. Haemoglobin concentration was estimated by cyanomethaemoglobin method [25].

2.4.2. Lipid Peroxides (LPO) Assay. The concentration of MDA, one of the markers of lipid peroxidation, was estimated in haemolysate following the method suggested by Placer et al. [26]. MDA contents were calculated on the basis of molar extinction coefficient of MDA-TBA complex at $548 \mathrm{~nm}$, that is, $1.56 \times 10^{-5} / \mathrm{mol} / \mathrm{cm}$, and expressed in terms of $\mu \mathrm{mol}$ of $\mathrm{MDA} / \mathrm{mg}$ of haemoglobin.

2.4.3. Full Thiol Content Assay. The concentration of total thiol in RBC suspension was estimated by 5,5-dithiobis-(2nitro-benzoic acid) (DTNB) method as per the procedure of Prins and Loos [27]. Thiol concentration in the test sample was calculated by employing the molar extinction coefficient of DTNB-GSH conjugate ( $\eta \mathrm{mol} / \mathrm{mg}$ of haemoglobin), $13600 / \mathrm{M} / \mathrm{cm}$.

2.4.4. Glutathione Peroxidase (GSH-Px) Assay. GSH-Px activity was determined by the method of Paglie and Valentie [28]. Activity was determined spectrophotometrically by coupling the oxidation of glutathione and NADPH using glutathione reductase. GSH-Px activity was standardized against protein concentrations and expressed as NADPH $\eta \mathrm{mol}$ oxidized per min per $\mathrm{mg}$ of haemoglobin $(\mathrm{mU} / \mathrm{mg}$ $\mathrm{Hb})$ by using the molar extinction coefficient $(\varepsilon)$ of 6200 at $340 \mathrm{~nm}$.

2.4.5. Glutathione-S-Transferase (GST). The GST activity in erythrocytes was determined according to the standard procedure of Habig et al. [29]. The specific activity of GST is expressed as mmol of GSH-CDNB conjugate formed/min/ mg of haemoglobin using an extinction coefficient of 9.6/ $\mathrm{mM} / \mathrm{cm}$.

2.4.6. Superoxide Dismutase (SOD) Assay. SOD activity in haemolysate was measured by using nitro blue tetrazolium as a substrate after suitable dilution as per the method suggested by Minami and Yoshikawa [30]. One unit of SOD activity was defined as the amount of enzyme that inhibited autooxidation by $50 \%$ under the given experimental condition, and the values were expressed as U/mg of haemoglobin.

2.4.7. Catalase (CAT) Assay. CAT activity in haemolysate was estimated by using $\mathrm{H}_{2} \mathrm{O}_{2}$ as a substrate as per the method of Bergmayer [31]. One unit of activity is equal to $\mathrm{mmol}$ of $\mathrm{H}_{2} \mathrm{O}_{2}$ degraded per min and is expressed as units/mg of haemoglobin.

\subsection{Apoptosis Assay}

2.5.1. Peripheral Blood Leukocytes (PBL) Isolation. The aliquot of $400 \mu \mathrm{L}$ of whole blood samples was added into appropriate tubes and centrifuged at $200 \times \mathrm{g}$. The supernatant plasma was discarded, and sediment cells containing buffy coat were washed with phosphate-buffered saline (PBS; $\mathrm{pH}$ 7.4). After removing the PBS, the samples were incubated in $\mathrm{NH}_{4} \mathrm{Cl}$ buffer $\left(0.15 \mathrm{M} \mathrm{NH}_{4} \mathrm{Cl}, 10 \mathrm{mM} \mathrm{NaHCO}_{3}\right.$ [pH 7.4]) for $7-10 \mathrm{~min}$ at $4^{\circ} \mathrm{C}$ to destroy the erythrocytes. For complete lysis of erythrocytes, the treatment was repeated once again, followed by two washes in $\mathrm{Ca}^{2+}-\mathrm{Mg}^{2+}$-free PBS (PBS-A), and supplemented with $0.035 \%(\mathrm{w} / \mathrm{v})$ EDTA, and centrifugation was at $400 \times \mathrm{g}$ for $10 \mathrm{~min}$ at $4^{\circ} \mathrm{C}$. Finally, isolated PBL were kept on ice until further processing.

2.5.2. Annexin V Binding Assay to Detect Apoptotic Cells. For quantification of apoptotic and dead cells, dual parameter analysis of Annexin V-EGFP Detection kit (GenScript, Centennial Avenue, Piscataway, USA) was used [32]. Briefly, isolated PBL $\left(0.5 \times 10^{6}\right)$ were washed twice with PBS by centrifugation at $2000 \mathrm{rpm}$ for $5 \mathrm{~min}$, and cells were resuspended in $500 \mu \mathrm{L}$ binding buffer and kept at $4^{\circ} \mathrm{C}$ for $30 \mathrm{~min}$. Finally, $5 \mu \mathrm{L}$ of annexin V-EFGP and $5 \mu \mathrm{L}$ of propidium iodide (PI) were added, and samples were incubated at room temperature for 10-15 min, away from light after thorough mixing. Final analysis of Annexin V-EGFP was performed in flow cytometer $(\mathrm{Ex}=488 \mathrm{~nm}$; $\mathrm{Em}=530)$ using the FITC signal detector (FL 1) and PI staining by the phycoerythrin emission signal detector (FL 2). For fluorescence balance, normal unstained cells were used as controls.

2.5.3. Assay of Depolarization Mitochondrial Membrane Potential $(\Delta \Psi m)$ to Detect Apoptotic Cells. For determination of depolarization of the mitochondrial membrane potential, Mitochondrial Apoptosis Detection Kit (JC-1) (GenScript, Centennial Avenue, Piscataway, USA) was used [33]. Depolarization of $\Delta \Psi \mathrm{m}$ was measured by using the lipophilic cationic dye $\left(5,5^{\prime}, 6,6^{\prime}\right.$-tetrachloro-1,1 $1^{\prime}, 3,3^{\prime}$-tetraethylbenzimidazolylcarbocyanine iodide, commonly known as JC-1) which selectively enters mitochondria. Briefly, isolated PBL $\left(0.5 \times 10^{6}\right)$ were washed twice with PBS by centrifugation at $2000 \mathrm{rpm}$ for $5 \mathrm{~min}$. One $\mu \mathrm{L}$ of JC- 1 was added to $500 \mu \mathrm{L}$ of prewarmed $1 \mathrm{X}$ incubation buffer, vortexed and mixed thoroughly, and used as a working solution. After mixing, the working solution was centrifuged at $13000 \mathrm{~g}$ for $1 \mathrm{~min}$, and the supernatant was transferred carefully for removing the particles. The cells were suspended with $500 \mu \mathrm{L}$ of JC-1 working solution and incubated at $37^{\circ} \mathrm{C}$ in a humidified 
incubator containing $5 \% \mathrm{CO}_{2}$ for $15-20 \mathrm{~min}$. Further, the cell suspensions were centrifuged at $2000 \mathrm{rpm}$ for $3 \mathrm{~min}$ at $37^{\circ} \mathrm{C}$, and the supernatant was discarded. Sediment cells were resuspended with $500 \mu \mathrm{L}$ of $1 \mathrm{X}$ incubation buffer and subjected to centrifugation at $2000 \mathrm{rpm}$ for $3 \mathrm{~min}$ at $37^{\circ} \mathrm{C}$. This step was repeated again, and finally, cells were suspended with $500 \mu \mathrm{L}$ of prewarmed $1 \mathrm{X}$ incubation buffer and analyzed immediately by flow cytometer. Mitochondria containing JC-1 aggregates in the healthy cells were detected in the propidium iodide channels (FL 2), and JC-1 monomer in the apoptotic cells was detected in the FITC channels (FL 1).

2.6. Statistical Analysis. Comparisons between the groups were performed using the MANOVA and post-hoc Tukey's tests. The level of statistical significance for all the comparisons made was established at $P \leq 0.05$.

\section{Results}

Microscopical examination of skin scrapings of dogs with sarcoptic mange revealed the presence of very high numbers of eggs, developing and adult mites per microscopic field before the start of the therapy. Partial anorexia was noted in all diseased dogs. By day 14, the parasitological cure rates in groups $\mathrm{A}, \mathrm{B}$, and $\mathrm{C}$ were $75 \%, 87.5 \%$, and $25 \%$, respectively. A $100 \%$ parasitological cure rate was found in groups A and $B$ by day 21 after therapy, while in ivermectin alone treated dogs (group C), only 50\% and 75\% parasitological cure could be achieved by days 21 and 28 after therapy, respectively.

Percent improvements of SSLSs for clinical recovery by days 14 and 28 are depicted in Table 1 . By day 14, ivermectin + CFE treated dogs (group A) revealed $73.56 \%$ improvement of SSLSs, while by day 28 , the improvement could be achieved up to $90.08 \%$. The ivermectin + NAC treated dogs (group B) revealed $72.75 \%$ improvement in SSLSs by day 14 after therapy, while by day 28 , it was $91.73 \%$. However, by days 14 and 28, the percent improvements of SSLSs for ivermectin alone treated dogs (group C) were $40.95 \%$ and $61.37 \%$, respectively (Table 1 ).

Both studied adjunctive therapies (CFE and NAC) revealed significant $(P \leq 0.01)$ improvement in the primary and secondary clinical evaluation scores in comparison with ivermectin alone treated dogs at the time point of evaluations. The improvements in CFE treated dogs were also comparable to those in the NAC (standard) treated dogs, and no significant difference existed for all clinical evaluation parameters at the time point of evaluations. No adverse drug reactions were observed in any group of dogs treated with CFE and NAC along with ivermectin or with ivermectin alone.

The means \pm S.D for oxidative stress markers of diseased and healthy dogs before and after receiving therapy are depicted in Table 2 . On day 0 , dogs with sarcoptic mange revealed significantly $(P \leq 0.001)$ higher lipid peroxides contents, lesser total thiol levels, and lowered glutathione peroxidase, glutathione-S-transferase, superoxide dismutase, and catalase activities in comparison with the healthy dogs. By day 28 after therapy, the altered oxidant/antioxidant balance was remarkably ameliorated towards normalcy in dogs
TABLE 1: Comparison groups A, B, and C for secondary clinical efficacy criterion (SSLS) on days 0,14 , and 28 of therapy.

\begin{tabular}{lccc}
\hline Groups & Days & SSLS & Improvement (\%) \\
\hline Group A & 0 & $15.13 \pm 1.46$ & - \\
(Ivermectin + CFE) & 14 & $4.00 \pm 1.06^{\mathrm{a}, \mathrm{b}}$ & 73.56 \\
& 28 & $1.50 \pm 0.75^{\mathrm{a}, \mathrm{b}}$ & 90.08 \\
\hline Group B & 0 & $15.12 \pm 2.58$ & - \\
(Ivermectin + NAC) & 14 & $4.12 \pm 1.45^{\mathrm{a}, \mathrm{b}}$ & 72.75 \\
& 28 & $1.25 \pm 1.03^{\mathrm{a}, \mathrm{b}}$ & 91.73 \\
\hline \multirow{2}{*}{ Group C } & 0 & $15.87 \pm 1.35$ & - \\
(Ivermectin) & 14 & $9.37 \pm 2.19$ & 40.95 \\
& 28 & $6.13 \pm 1.95^{\mathrm{a}}$ & 61.37 \\
\hline
\end{tabular}

${ }^{a}$ Statistically significant differences $(P \leq 0.01)$, when compared with the day 0 values.

${ }^{\mathrm{b}}$ Statistically significant differences $(P \leq 0.01)$, when compared with the same days values of a group.

of groups A and B. The increased erythrocytes MDA contents of these groups were significantly lowered $(P \leq 0.001)$ in comparison with the values pertaining on day 0 . Erythrocytes MDA contents of these dogs on day 28 also achieved a level comparable to that of the healthy dogs. A significant enhancement $(P \leq 0.001)$ of the total thiol contents and lowered activities of GSH-Px, GST, SOD, and CAT was also revealed in these groups when compared with the values pertaining on day 0 and was found to be comparable to that of healthy dogs. However, the dogs treated only with ivermectin (group C) could not achieve the comparable values to those of healthy dogs by day 28 after therapy.

The means \pm S.D for apoptotic markers of all groups before and after therapy are depicted in Table 3. On day 0 , the percentage of peripheral leukocytes with externalization of phosphatidylserine on cell membrane (apoptotic cells) was significantly $(P \leq 0.001)$ increased in all dogs with sarcoptic mange in comparison with the healthy dogs. These dogs also revealed a significantly $(P \leq 0.001)$ higher percentage of leukocytes with depolarized mitochondria $(\% \Delta \Psi \mathrm{m})$. By day 28 , the increased percentage of apoptotic leukocytes (both the leukocytes with externalization of phosphatidylserine and depolarized mitochondria) of groups $A$ and $B$ was significantly ameliorated $(P \leq 0.001)$ in comparison with the values pertaining on day 0 and became comparable to that of healthy dogs. However, the dogs treated only with ivermectin (group C) could not achieve the comparable values to those of healthy dogs by day 28 after therapy. Further, no adverse effects have been recorded in both CFE and NAC adjunctively supplemented dogs, and the administered dose regimen of these supplementations was found to be safe.

\section{Discussion}

In the present study, we found that the dogs with sarcoptic mange were in a state of significant oxidative stress. The results of the present study are in agreement with the earlier scientific reports where altered antioxidant systems with states of oxidative stress have been demonstrated with various 
TABLE 2: The markers of oxidative stress (lipid peroxides, reduced glutathione, glutathione peroxidase, glutathione-S-transferase, superoxide dismutase, and catalase) in peripheral blood of dogs with sarcoptic mange and healthy control dogs at days 0 and 28 of therapy (mean \pm SD).

\begin{tabular}{|c|c|c|c|c|c|c|c|}
\hline Groups & Days & $\begin{array}{c}\mathrm{LPO} \\
\mu \mathrm{mol} \\
\mathrm{MDA} / \mathrm{mg} \mathrm{Hb}\end{array}$ & $\begin{array}{c}\text { Total thiol } \\
\eta \mathrm{mol} / \mathrm{mg} \mathrm{Hb}\end{array}$ & $\begin{array}{l}\text { GSH-Px } \\
\mathrm{mU} / \mathrm{mg} \mathrm{Hb}\end{array}$ & $\begin{array}{c}\text { GST } \\
\mathrm{mU} / \mathrm{mg} \mathrm{Hb}\end{array}$ & $\begin{array}{c}\mathrm{SOD} \\
\mathrm{U} / \mathrm{mg} \mathrm{Hb}\end{array}$ & $\begin{array}{c}\text { CAT } \\
\mathrm{K} / \mathrm{mg} \mathrm{Hb}\end{array}$ \\
\hline \multirow{2}{*}{$\begin{array}{l}\text { Group A } \\
(\text { Ivermectin }+ \text { CFE })\end{array}$} & 0 & $1.945 \pm 0.15^{\mathrm{a}}$ & $13.62 \pm 1.6^{\mathrm{a}}$ & $6236.12 \pm 192^{\mathrm{a}}$ & $0.602 \pm 0.06^{\mathrm{a}}$ & $0.737 \pm 0.10^{\mathrm{a}}$ & $89.25 \pm 11^{\mathrm{a}}$ \\
\hline & 28 & $0.843 \pm 0.09^{\mathrm{b}}$ & $33.90 \pm 3.9^{\mathrm{b}}$ & $8823.12 \pm 206^{\mathrm{b}}$ & $0.931 \pm 0.06^{\mathrm{b}}$ & $1.082 \pm 0.06^{\mathrm{b}}$ & $153.25 \pm 9^{b}$ \\
\hline \multirow{2}{*}{$\begin{array}{l}\text { Group B } \\
(\text { Ivermectin + NAC ) }\end{array}$} & 0 & $1.875 \pm 0.12^{\mathrm{a}}$ & $14.78 \pm 2.5^{\mathrm{a}}$ & $6153.15 \pm 159^{\mathrm{a}}$ & $0.618 \pm 0.06^{\mathrm{a}}$ & $0.697 \pm 0.12^{\mathrm{a}}$ & $89.62 \pm 13^{\mathrm{a}}$ \\
\hline & 28 & $0.808 \pm 0.12^{\mathrm{b}}$ & $34.11 \pm 2.5^{\mathrm{b}}$ & $8792.75 \pm 309^{\mathrm{b}}$ & $0.908 \pm 0.07^{\mathrm{b}}$ & $1.117 \pm 0.05^{\mathrm{b}}$ & $144.50 \pm 12^{\mathrm{b}}$ \\
\hline \multirow{2}{*}{$\begin{array}{l}\text { Group C } \\
\text { (Ivermectin) }\end{array}$} & 0 & $1.947 \pm 0.09^{\mathrm{a}}$ & $14.99 \pm 2.0^{\mathrm{a}}$ & $6235.12 \pm 197^{\mathrm{a}}$ & $0.592 \pm 0.06^{\mathrm{a}}$ & $0.747 \pm 0.11^{\mathrm{a}}$ & $95.25 \pm 7.2^{\mathrm{a}}$ \\
\hline & 28 & $1.270 \pm 0.05$ & $21.33 \pm 1.7$ & $7587.15 \pm 364$ & $0.712 \pm 0.08$ & $0.866 \pm 0.07$ & $117.75 \pm 4.2$ \\
\hline $\begin{array}{l}\text { Group D } \\
\text { (Healthy) }\end{array}$ & 0 & $0.720 \pm 0.07$ & $36.83 \pm 2.5$ & $8963.62 \pm 113$ & $0.987 \pm 0.05$ & $1.188 \pm 0.03$ & $176.25 \pm 8.2$ \\
\hline
\end{tabular}

${ }^{a}$ Statistically significant differences $(P \leq 0.001)$ when compared with group $\mathrm{D}$.

${ }^{\mathrm{b}}$ Statistically significant differences $(P \leq 0.001)$ when compared with the values pertaining at day 0 .

TABLE 3: Flow cytometric analysis of apoptotic leukocytes with externalization of phosphatidylserine (PS) and depolarized mitochondria $(\triangle \Psi \mathrm{m})$ in peripheral blood of dogs with sarcoptic mange and healthy control groups at days 0 and 28 of therapy (mean \pm SD).

\begin{tabular}{lccc}
\hline Groups & Days & $\begin{array}{c}\text { Leukocytes } \\
\text { with external } \\
\text { PS }(\%)\end{array}$ & $\begin{array}{c}\text { Leukocytes } \\
\text { with } \Delta \Psi \mathrm{m} \\
(\%)\end{array}$ \\
\hline $\begin{array}{lccc}\text { Group A } \\
\text { (Ivermectin + CFE) }\end{array}$ & 28 & $21.87 \pm 2.78^{\mathrm{a}}$ & $\begin{array}{c}24.67 \pm 2.34^{\mathrm{a}} \\
3.83 \pm 1.50^{\mathrm{b}}\end{array}$ \\
\hline $\begin{array}{l}\text { Group B } \\
\text { (Ivermectin + NAC) }\end{array}$ & 28 & $21.38 \pm 3.10^{\mathrm{a}}$ & $29.00 \pm 1.48^{\mathrm{b}}$ \\
\hline $\begin{array}{l}\text { Group C } \\
\text { (Ivermectin) }\end{array}$ & 0 & $22.92 \pm 1.31^{\mathrm{a}}$ & $23.74 \pm 2.17^{\mathrm{a}}$ \\
\hline $\begin{array}{l}\text { Group D } \\
\text { (Healthy) }\end{array}$ & 28 & $13.89 \pm 1.67$ & $17.40 \pm 1.47$ \\
\hline
\end{tabular}

$\overline{{ }^{a} \text { Statistically significant differences }(P \leq 0.001) \text { when compared with group }}$ D.

${ }^{\mathrm{b}}$ Statistically significant differences $(P<0.001)$ when compared with the values pertaining at day 0 .

parasitic skin infestations in animals, including sarcoptic mange [14-16, 34-36]. Recently, we have demonstrated that the dogs with sarcoptic mange are in a state of severe oxidative stress, and the percentage of apoptotic leukocytes in peripheral blood of these dogs is remarkably higher as compared to the healthy controls [17]. Amelioration of the altered oxidant/antioxidant balance towards normalcy in ivermectin + CFE treated dogs indicates potential antioxidant action of the adjunctive therapy.

Lipid peroxidation can be harmful for skin due to alteration in the structure and permeability [37]. Various scientific reports have demonstrated the versatile medicinal activities of Calendula extracts including antitumoral [38], antiinflammatory, wound healing [39], hepato- and renoprotective [40], and antioxidant activities [22, 41]. In clinical studies, Calendula is highly efficacious in the prevention of acute dermatitis in cancer patients undergoing postoperative irradiation [42]. In vitro free radical quenching of potential
Calendula flower extracts has been also reported [43]. Bilia et al. [44] identified narcissin, rutin, isoquercitrin, quercetin-3O-rutinosylrhamnoside, isorhamnetin-3-O-rutinosylrhamnoside, isorhamnetin-3-O-glucosylglucoside, and isorhamnetin-3-O-glucoside in C. officinalis flowers. In the last decade, C. officinalis is used in tinctures and creams and is valuable for positive effect on skin diseases [22, 45]. The antioxidant potential of $C$. officinalis extracts against lipid peroxidation of rat liver microsomes by acting as a potent free radical scavenger and an antioxidant has been reported by earlier works $[46,47]$.

Results of the present study signify the potential triumph of CFE against Sarcoptes-induced lipid peroxidation. Amelioration of increased MDA content might have endorsed faster remedy of injured skin in the infested dogs. The current study also demonstrates that CFE adjunctive treatment has significantly improved the lower total thiol content and reduced GSH-Px, GST, SOD, and CAT activities towards normalcy by day 28 in dogs with sarcoptic mange. Findings of the current study indicate the potential protective activity of CFE against Sarcoptes-induced oxidative stress. The encompassment of a large quantity of antioxidant compounds (flavonoids and polyphenols) in the Calendula flowers might have resulted in remarkable amelioration of sarcoptic mangeinduced oxidative stress. Recently, it has been reported that the antioxidant action of nutritional antioxidants is conferred not only by the direct free radicals quench but also by the generation of signals for the induction of protective enzymes via their paradoxical oxidative activation of the Nrf2 (NF-E2related factor 2) signaling pathway [48]. Thus, the possibilities of activating the Nrf2 signaling pathway in the significant ameliorations of the protective antioxidant enzymes activities in CFE administered dogs cannot be overlooked.

Resistance to diseases is a multigenic trait governed mainly by the immune system and its interactions with many physiologic and environmental factors. In the adaptive immunity, T-cell and B-cell responses, the specific recognition of antigens, and interactions between antigen presenting cells, $\mathrm{T}$ cells, and $\mathrm{B}$ cells are essential. These interactions occur through a network of mediator proteins such as the molecules 
of the major histocompatibility complex (MHC), T-cell receptors, and immunoglobulins and secreted proteins such as the cytokines and antibodies. The results of the current study demonstrate remarkable deterrence of Sarcoptesinduced apoptosis in peripheral leukocytes in CFE treated dogs and suggest the possible immunorestorative potential of CFE against hasty immunoaging. This phenomenon may be elucidated by the free radicals scavenging and immunomodulatory potential of CFE. By ameliorating the oxidative stress, CFE may be enhancing the compromised immune status of the Sarcoptes-infested dogs, leading to the inhibition of proliferation of mites.

As we found that the clinical recovery and parasitological cure rates were faster in ivermectin + CFE treated dogs, the supplementation of CFE along with ivermectin might have shifted the altered oxidant/antioxidant balance towards normalcy with a faster rate. Recently, we have demonstrated a faster clinical recovery and shifting of oxidative imbalance toward normalcy by adjunct therapy with antioxidants in Psoroptes cuniculi-infested rabbits [49]. The restoration of antioxidants and amelioration of lipid peroxidation in CFE treated dogs might be involved in faster clinical and parasitological cure. Lipid peroxidation can be harmful for skin due to alterations in the structure and permeability [37]. CFE might have a complementary effect with ivermectin as compromised antioxidant defense systems of infested dogs and healing effect of ivermectin remarkably improved by day 28 after therapies. Findings of the present study indicate a potential role of CFE in faster clinical recovery in Sarcoptesinfested dogs. Previous scientific reports have demonstrated the skin healing activities of Calendula in various skin disorders due to its multitude of properties; for instance, anti-inflammation, stimulation of epithelialization, and an increase in gelatinase activities $[22,41]$. Results of the present study signify the faster parasitological cure; in this context, CFE might have indirectly augmented the miticidal effect of ivermectin. This may be an outcome of various activities including immunomodulatory and antioxidant actions of CFE, promoting the animal body to combat against the Sarcoptes mites.

In conclusion, Calendula officinalis flower extracts have remarkable antioxidant potential contributing to the deterrence of Sarcoptes-induced oxidative discrepancy in dogs. They also have accomplishments against Sarcoptes-induced immunological misbalance, can avert and/or ameliorate the hasty aging of leukocytes, and consequently can augment miticidal activity of ivermectin by improving compromised immunity. Clinicians may recommend CFE as an adjunctive remedy along with the miticide to manage clinical canine sarcoptic mange. Additionally, large-scale studies are needed for these assumptions to be confirmed.

\section{References}

[1] S. Bornstein, T. Mörner, and W. M. Samuel, "Sarcoptes scabiei and sarcoptic mange," in Parasitic Diseases of Wild Mammals, W. M. Samuel, M. J. Pybus, and A. A. Kocan, Eds., pp. 107-119, Iowa State University Press, Ames, Iowa, USA, 2nd edition, 2001.
[2] D. B. Pence and E. Ueckermann, "Sarcoptic manage in wildlife," Revue Scientifique et Technique, vol. 21, no. 2, pp. 385-398, 2002.

[3] D. J. Kemp, S. F. Walton, P. Harumal, and B. J. Currie, "The scourge of scabies," Biologist, vol. 49, no. 1, pp. 19-24, 2002.

[4] N. D. Giadinis, R. Farmaki, N. Papaioannou, E. Papadopoulos, H. Karatzias, and A. F. Koutinas, "Moxidectin efficacy in a goat herd with chronic and generalized sarcoptic mange," Veterinary Medicine, vol. 2011, Article ID 476348, 4 pages, 2011.

[5] M. P. Dagleish, Q. Ali, R. K. Powell, D. Butz, and M. H. Woodford, "Fatal Sarcoptes scabiei infection of blue sheep (Pseudois nayaur) in Pakistan," Journal of Wildlife Diseases, vol. 43, no. 3, pp. 512-517, 2007.

[6] P. Daszak, A. A. Cunningham, and A. D. Hyatt, "Emerging infectious diseases of wildlife: threats to biodiversity and human health," Science, vol. 287, no. 5452, pp. 443-449, 2000.

[7] G. C. Fthenakis, E. Papadopoulos, C. Himonas, L. Leontides, S. Kritas, and J. Papatsas, "Efficacy of moxidectin against sarcoptic mange and effects on milk yield of ewes and growth of lambs," Veterinary Parasitology, vol. 87, no. 2-3, pp. 207-216, 2000.

[8] G. C. Fthenakis, A. Karagiannidis, C. Alexopoulos, C. Brozos, and E. Papadopoulos, "Effects of sarcoptic mange on the reproductive performance of ewes and transmission of Sarcoptes scabiei to newborn lambs," Veterinary Parasitology, vol. 95, no. 1, pp. 63-71, 2001.

[9] J. Heukelbach, T. Wilcke, B. Winter, and H. Feldmeier, "Epidemiology and morbidity of scabies and pediculosis capitis in resource-poor communities in Brazil," British Journal of Dermatology, vol. 153, no. 1, pp. 150-156, 2005.

[10] B. J. Currie, P. Harumal, M. McKinnon, and S. F. Walton, "First documentation of in vivo and in vitro ivermectin resistance in Sarcoptes scabiei," Clinical Infectious Diseases, vol. 39, no. 1, pp. e8-e12, 2004.

[11] S. M. Bradberry, S. A. Cage, A. T. Proudfoot, and J. A. Vale, "Poisoning due to pyrethroids," Toxicological Reviews, vol. 24, no. 2, pp. 93-106, 2005.

[12] H. Sanderson, B. Laird, L. Pope et al., "Assessment of the environmental fate and effects of ivermectin in aquatic mesocosms," Aquatic Toxicology, vol. 85, no. 4, pp. 229-240, 2007.

[13] Y. Terada, N. Murayama, H. Ikemura, T. Morita, and M. Nagata, "Sarcoptes scabiei var. canis refractory to ivermectin treatment in two dogs," Veterinary Dermatology, vol. 21, no. 6, pp. 608-612, 2010.

[14] U. Dimri, M. C. Sharma, D. Swarup, R. Ranjan, and M. Kataria, "Alterations in hepatic lipid peroxides and antioxidant profile in Indian water buffaloes suffering from sarcoptic mange," Research in Veterinary Science, vol. 85, no. 1, pp. 101-105, 2008.

[15] I. Camkerten, T. Sahin, G. Borazan, A. Gokcen, O. Erel, and A. Das, "Evaluation of blood oxidant/antioxidant balance in dogs with sarcoptic mange," Veterinary Parasitology, vol. 161, no. 1-2, pp. 106-109, 2009.

[16] M. A. Saleh, O. M. Mahran, and M. B. Al-Salahy, "Circulating oxidative stress status in dromedary camels infested with sarcoptic mange," Veterinary Research Communications, vol. 35, no. 1, pp. 35-45, 2011.

[17] S. K. Singh, U. Dimri, M. C. Sharma, D. Swarup, and B. Sharma, "Determination of oxidative status and apoptosis in peripheral blood of dogs with sarcoptic mange," Veterinary Parasitology, vol. 178, no. 3-4, pp. 330-338, 2011.

[18] A. K. Atoui, A. Mansouri, G. Boskou, and P. Kefalas, "Tea and herbal infusions: their antioxidant activity and phenolic profile," Food Chemistry, vol. 89, no. 1, pp. 27-36, 2005. 
[19] L. Le Marchand, "Cancer preventive effects of flavonoids-a review," Biomedicine and Pharmacotherapy, vol. 56, no. 6, pp. 296-301, 2002.

[20] E. Middleton Jr., C. Kandaswami, and T. C. Theoharides, “The effects of plant flavonoids on mammalian cells: implications for inflammation, heart disease, and cancer," Pharmacological Reviews, vol. 52, no. 4, pp. 673-751, 2000.

[21] H. K. Kang, D. Ecklund, M. Liu, and S. K. Datta, "Apigenin, a non-mutagenic dietary flavonoid, suppresses lupus by inhibiting autoantigen presentation for expansion of autoreactive Th1 and Th17 cells," Arthritis Research and Therapy, vol. 11, no. 2, article R59, 13 pages, 2009.

[22] Y. M. Fonseca, C. D. Catini, F. T. Vicentini, A. Nomizo, R. F. Gerlach, and M. J. Fonseca, "Protective effect of Calendula officinalis extract against UVB-induced oxidative stress in skin: evaluation of reduced glutathione levels and matrix metalloproteinase secretion," Journal of Ethnopharmacology, vol. 127, no. 3 , pp. 596-601, 2010.

[23] T. A. Re, D. Mooney, E. Antignac et al., "Application of the threshold of toxicological concern approach for the safety evaluation of calendula flower (Calendula officinalis) petals and extracts used in cosmetic and personal care products," Food and Chemical Toxicology, vol. 47, no. 6, pp. 1246-1254, 2009.

[24] K. Krieger, J. Heine, P. Dumont, and K. Hellmann, "Efficacy and safety of imidacloprid $10 \%$ plus moxidectin $2.5 \%$ spot-on in the treatment of sarcoptic mange and otoacariosis in dogs: results of a European field study," Parasitology Research, vol. 97, supplement 1, pp. S81-S88, 2005.

[25] E. J. Vankampen and W. G. Zinglstra, "Calorimetric determination of haemoglobin," Clinica Chimica Acta, vol. 6, p. 3588, 1961.

[26] Z. A. Placer, L. L. Cushman, and B. C. Johnson, "Estimation of product of lipid peroxidation (malonyl dialdehyde) in biochemical systems," Analytical Biochemistry, vol. 16, no. 2, pp. 359-364, 1966.

[27] H. K. Prins and J. A. Loos, "Glutathione," in Biochemical Methods in Red Cell Genetics, pp. 127-129, Academic Press, New York, NY, USA, 1969.

[28] D. E. Paglie and W. N. Valentie, "Studies on quantitative and qualitative characterization of erythrocyte glutathione peroxidase," Journal of Laboratory and Clinical Medicine, vol. 70, pp. 158-169, 1967.

[29] W. H. Habig, M. J. Pabst, and W. B. Jakoby, "Glutathione S-transferases. The first enzymatic step in mercapturic acid formation," Journal of Biological Chemistry, vol. 249, no. 22, pp. 7130-7139, 1974.

[30] M. Minami and H. Yoshikawa, "A simplified assay method of superoxide dismutase activity for clinical use," Clinical Chemistry, vol. 63, no. 6, pp. 1258-1261, 1979.

[31] H. U. Bergmayer, "UV method of catalase assay," in Methods of Enzymatic Analysis, vol. 3, p. 273, Bansal, Weinheim Deer Field Beach, Fla, USA, 1983.

[32] I. Vermes, C. Haanen, H. Steffens-Nakken, and C. Reutelingsperger, "A novel assay for apoptosis. Flow cytometric detection of phosphatidylserine expression on early apoptotic cells using fluorescein labelled Annexin V," Journal of Immunological Methods, vol. 184, no. 1, pp. 39-51, 1995.

[33] C. Adrie, M. Bachelet, M. Vayssier-Taussat et al., "Mitochondrial membrane potential and apoptosis peripheral blood monocytes in severe human sepsis," American Journal of Respiratory and Critical Care Medicine, vol. 164, no. 3, pp. 389-395, 2001.
[34] M. Kanbur, O. Atalay, A. Ica, G. Eraslan, and Y. Cam, "The curative and antioxidative efficiency of doramectin and doramectin + vitamin AD3E treatment on Psoroptes cuniculi infestation in rabbits," Research in Veterinary Science, vol. 85, no. 2, pp. 291293, 2008.

[35] U. K. De and S. Dey, "Evaluation of organ function and oxidant/antioxidant status in goats with sarcoptic mange," Tropical Animal Health and Production, vol. 42, no. 8, pp. 1663-1668, 2010.

[36] U. Dimri, M. C. Sharma, A. Yamdagni, R. Ranjan, and M. M. S. Zama, "Psoroptic mange infestation increases oxidative stress and decreases antioxidant status in sheep," Veterinary Parasitology, vol. 168, no. 3-4, pp. 318-322, 2010.

[37] L. R. Portugal, L. R. Fernandes, V. S. Pietra-Pedroso, H. C. Santiago, R. T. Gazzinelli, and J. I. Alvarez-Leite, "Influence of low-density lipoprotein (LDL) receptor on lipid composition, inflammation and parasitism during Toxoplasma gondii infection," Microbes and Infection, vol. 10, no. 3, pp. 276-284, 2008.

[38] E. Jiménez-Medina, A. Garcia-Lora, L. Paco, I. Algarra, A. Collado, and F. Garrido, "A new extract of the plant Calendula officinalis produces a dual in vitro effect: cytotoxic anti-tumor activity and lymphocyte activation," BMC Cancer, vol. 6, article 119, 2006.

[39] K. Zitterl-Eglseer, S. Sosa, J. Jurenitsch et al., "Anti-oedematous activities of the main triterpendiol esters of marigold (Calendula officinalis L., Asteraceae)," Journal of Ethnopharmacology, vol. 57, no. 2, pp. 139-144, 1997.

[40] K. C. Preethi, G. Kuttan, and R. Kuttan, "Anti-inflammatory activity of flower extract of Calendula officinalis Linn. and its possible mechanism of action," Indian Journal of Experimental Biology, vol. 47, no. 2, pp. 113-120, 2009.

[41] V. Katalinic, M. Milos, T. Kulisic, and M. Jukic, "Screening of 70 medicinal plant extracts for antioxidant capacity and total phenols," Food Chemistry, vol. 94, no. 4, pp. 550-557, 2006.

[42] P. Pommier, F. Gomez, M. P. Sunyach, A. D’Hombres, C. Carrie, and X. Montbarbon, "Phase III randomized trial of Calendula officinalis compared with trolamine for the prevention of acute dermatitis during irradiation for breast cancer," Journal of Clinical Oncology, vol. 22, no. 8, pp. 1447-1453, 2004.

[43] A. K. Mishra, A. Mishra, and P. Chattopadhyay, "A pilot study on in vitro evaluation of flowers of Calendula officinalis (L) as natural anti-solar agent," Journal of Natural Pharmaceuticals, vol. 2, no. 2, pp. 77-79, 2011.

[44] A. R. Bilia, M. C. Bergonzi, S. Gallori, G. Mazzi, and F. F. Vincieri, "Stability of the constituents of Calendula, milk-thistle and passionflower tincture by LC-DAD and LC-MS," Journal of Pharmaceutical and Biomedical Analysis, vol. 30, no. 3, pp. 613624, 2002.

[45] J. Bernatoniene, R. Masteikova, J. Davalgiene et al., “Topical application of Calendula officinalis (L.): formulation and evaluation of hydrophilic cream with antioxidant activity," Journal of Medicinal Plant Research, vol. 5, no. 6, pp. 868-877, 2011.

[46] M. Albulescu, N. Alexa, and C. Cojan, "Calendula officinalis flower, source of extracts with antioxidant activity," Series Chemistry, vol. 13, no. 2, pp. 69-176, 2004.

[47] M. U. Khan, A. Rohilla, D. Bhatt, S. Afrin, S. Rohilla, and S. H. Ansari, "Diverse belongings of Calendula officinalis: an overview," International Journal of Pharmaceutical Sciences and Drug Research, vol. 3, no. 3, pp. 173-177, 2011.

[48] H. J. Forman, K. J. Davies, and F. Ursini, "How do nutritional antioxidants really work: nucleophilic tone and para-hormesis 
versus free radical scavenging in vivo," Free Radical Biology \& Medicine, 2013.

[49] S. K. Singh, U. Dimri, M. C. Sharma, D. Swarup, M. Kumar, and R. Tiwary, "Psoroptes cuniculi induced oxidative imbalance in rabbits and its alleviation by using vitamins A, D3, E, and $\mathrm{H}$ as adjunctive remedial," Tropical Animal Health and Production, vol. 44, no. 1, pp. 43-48, 2012. 


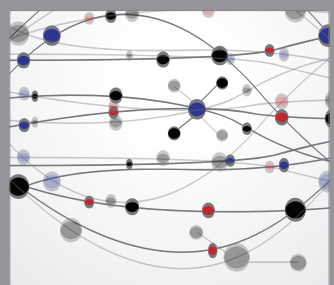

The Scientific World Journal
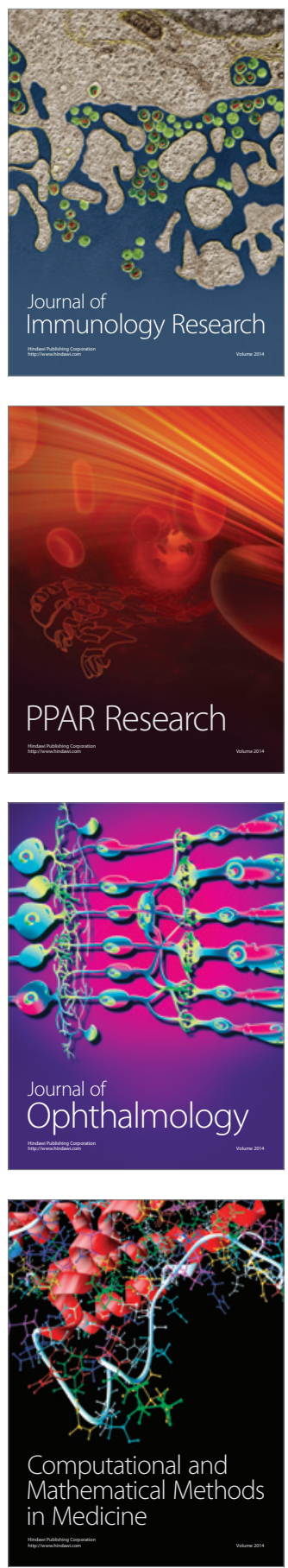

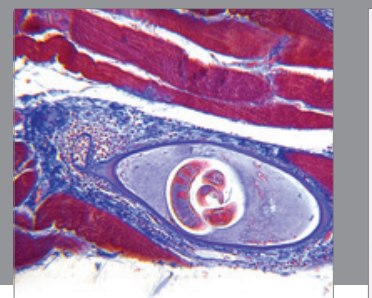

Gastroenterology

Research and Practice
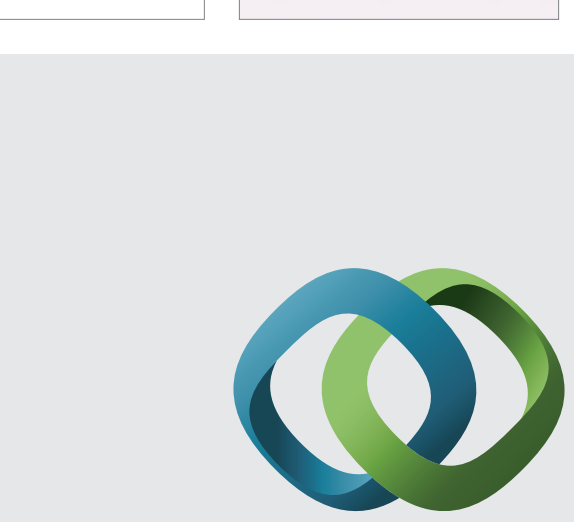

\section{Hindawi}

Submit your manuscripts at

http://www.hindawi.com
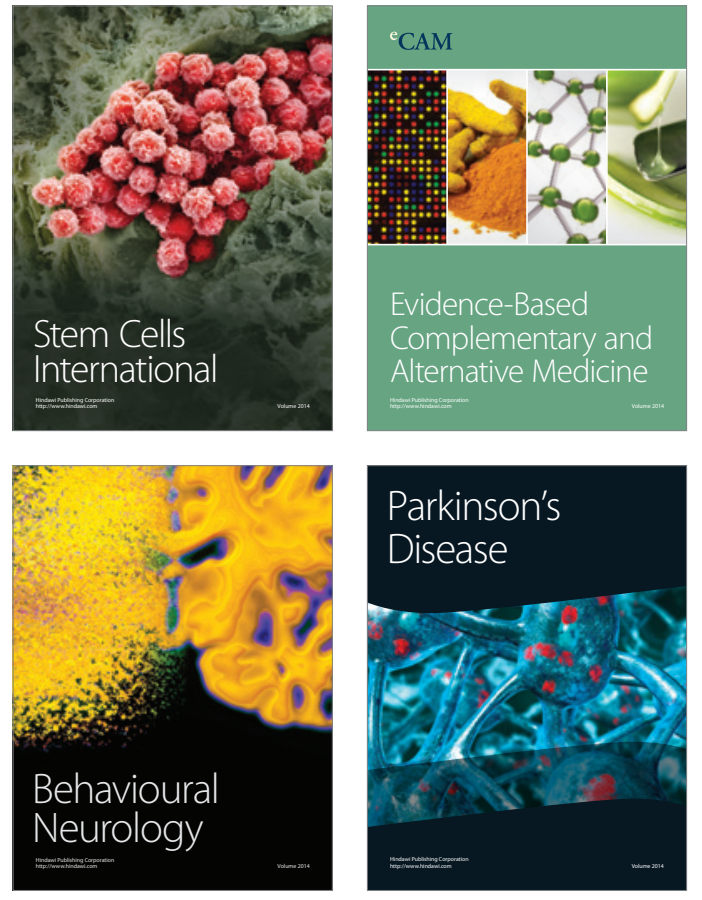
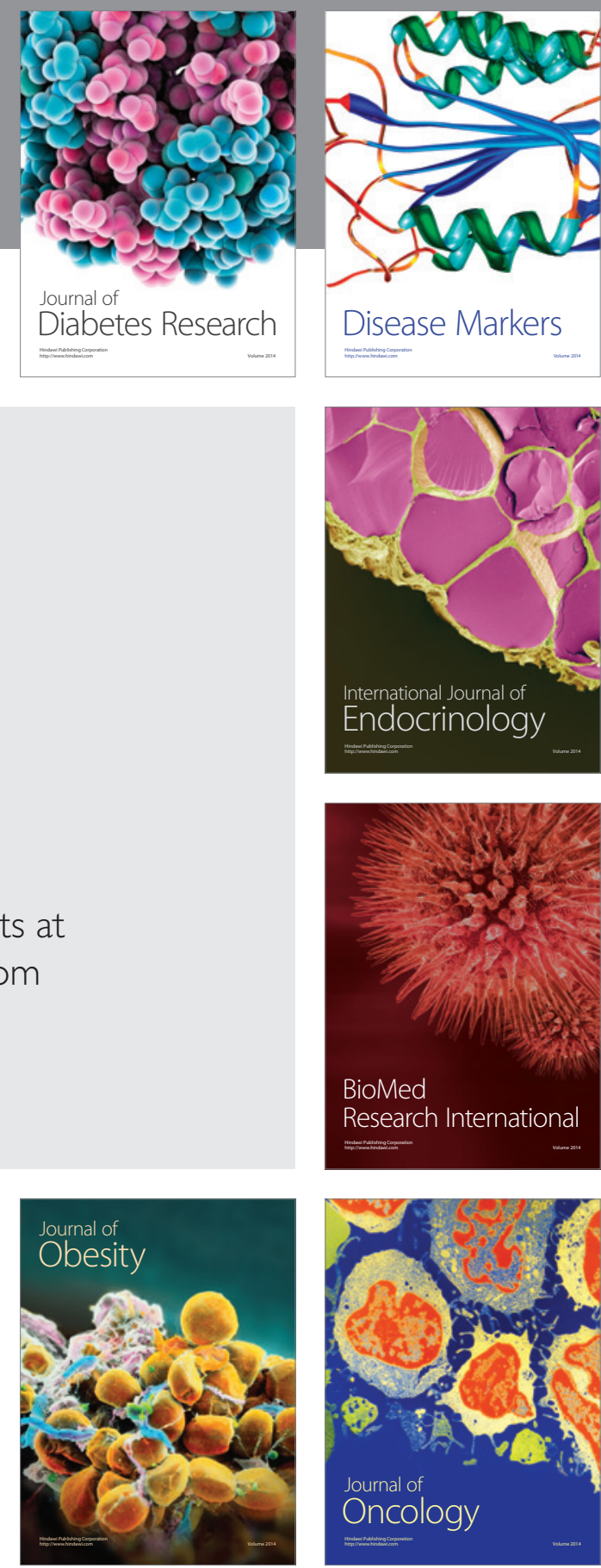

Disease Markers
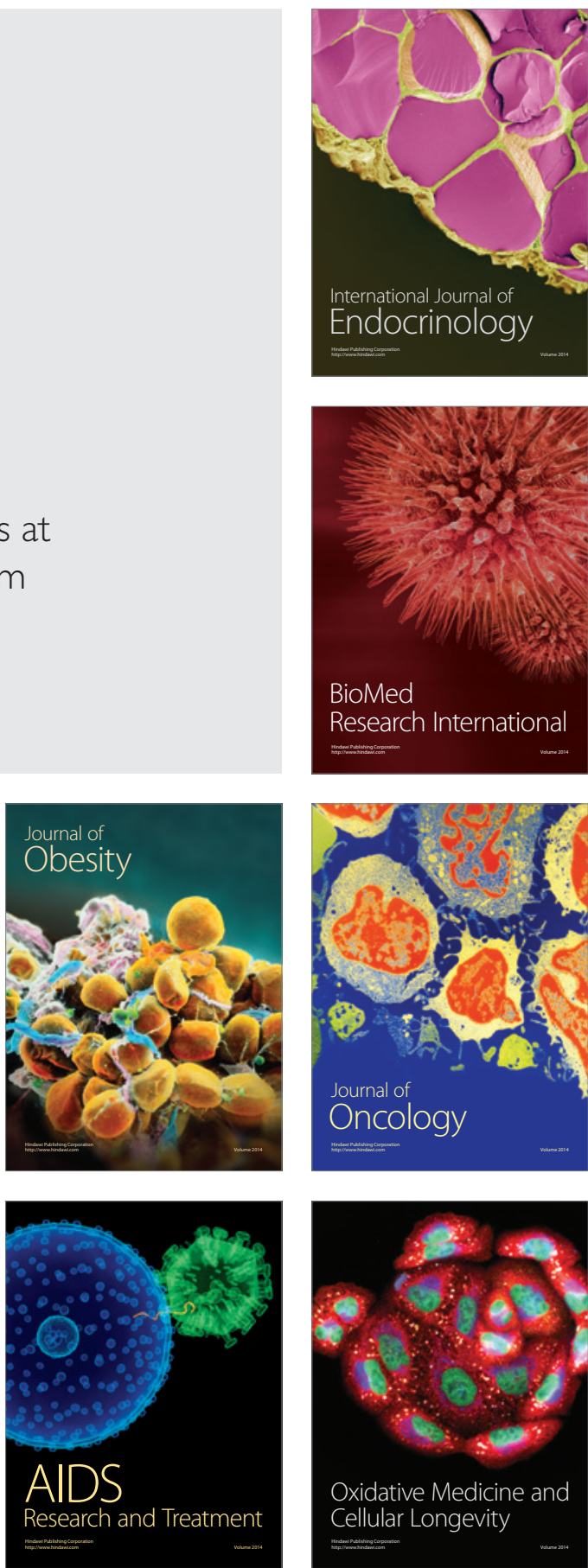